\title{
Upregulation of transforming growth factor-B1 gene in ankylosing spondylitis patients
}

\author{
Farin Vaez $^{1,2}$, Ali Farazmand ${ }^{2}$, Sarvenaz Shaaheen ${ }^{1,3}$, Shayan Mostafaei ${ }^{1,4}$, Ahmadreza Jamshidi ${ }^{{ }^{*}}$, Mahdi \\ Vojdanian $^{1}$, Ashkan Asadollahbaik ${ }^{1}$, Mahdi Mahmoudi ${ }^{1 *}$ \\ ${ }^{I}$ Rheumatology Research Center, Tehran University of Medical Sciences, Tehran, Iran. ${ }^{2}$ Department of Cell and Molecular Biology, \\ University of Tehran, Tehran, Iran. ${ }^{3}$ Students' Scientific Research Center, Tehran University of Medical Sciences, Tehran, Iran. \\ ${ }^{4}$ Department of Biostatistics, Faculty of medical sciences, Tarbiat Modares University, Tehran, Iran
}

\begin{abstract}
Ankylosing spondylitis is a chronic inflammatory disorder of the axial skeleton. The transforming growth factor-beta (TGF- $\beta$ ) is a cytokine that has the dual action of suppressing inflammatory cytokines and augmenting inflammation. The role of this cytokine in ankylosing spondylitis is still unknown. The current study purposed to determine $T G F-B 1$ gene expression in ankylosing spondylitis. A case-control study of 48 ankylosing spondylitis patients and 47 age- and gender-matched healthy controls was conducted. Quantitative polymerase chain reaction with specific primers was used to measure the expression of $T G F-B 1$ gene in participants. Clinical indices of the disease, including the Bath Ankylosing Spondylitis Disease Activity Index (BASDAI), Metrology Index (BASMI), Functional Index (BASFI), and AS quality of life (ASQoL) were determined. The expression of $T G F-B 1$ was compared between cases and controls. Correlations between gene expression and clinical indices were assessed. The expression of TGF-B1 was significantly higher in AS patients than in the control group $(P$-value < $0.0001)$. The change was 1.32 -fold. There was no significant correlation between gene expression and AS clinical indices. The increase in $T G F-B 1$ expression possibly demonstrates its activity in AS disease either in a regulatory role as a response to inflammation in the body or as the augmentation of inflammation which exacerbates the disease. Further research needs to be done on this issue to resolve this uncertainty.
\end{abstract}

Keywords: ankylosing spondylitis, clinical manifestations, expression, transforming growth factor-beta.

\section{Introduction}

Ankylosing spondylitis (AS) is a chronic inflammatory rheumatic disorder of the axial skeleton. It can also cause peripheral joint and enthesis inflammation and extraarticular involvements. Initial symptoms are usually inflammatory back and gluteal pain caused by sacroiliitis. Chronic inflammation in the spine and axial joints leads to ankylosis, formation of syndesmophytes, and osteoporosis. Therefore, most patients suffer from loss of spinal mobility [1]. AS is usually first noticed under 30 years of age [2]. The prevalence of the disease is $0.12 \%$ in urban areas of Iran [3]. Genetic factors play an important role in AS, and among these factors human leukocyte antigen-B27 (HLA-B27) has the strongest association with this disease [4].

Transforming growth factor- $\beta$ (TGF- $\beta$ ) is a pleiotropic cytokine which has an important role in the formation and repair of cartilage and bone tissues. In fact, injection of this cytokine into the periosteal sheath of rat bones causes cartilage formation, which then leads to bone formation after injections are ceased [5]. It also seems that, in the presence of TGF- $\beta$, B-cells switch to the production of $\operatorname{IgA}[6]$, which has a higher concentration in AS patients [7]. Therefore, TGF- $\beta$ can possibly be a key cytokine in the pathogenesis of AS disease, in which inflammation, ankylosis, and bone formation are the main phenomena.

TGF- $\beta$ can act as either a regulatory or an inflammatory agent. This cytokine is mostly known for its regulatory role, which is done through inhibiting the proliferation and differentiation of self-reactive $\mathrm{T}$ cells. Other mechanisms of immune regulation include helping regulatory $\mathrm{T}$ cells (Treg cells) to survive and to differentiate. This cytokine induces peripheral tolerance and can have a protective effect on autoimmune diseases. The inflammatory role of TGF- $\beta$

\footnotetext{
* Corresponding Authors: Ahmad Reza Jamshidi, Email: jamshida@tums.ac.ir; Tel/Fax: +98-21-88220065; and Mahdi Mahmoudi, Email: mahmoudim@tums.ac.ir, Tel: +98-21-88220067
}

Received: 04 January 2017; Accepted: 01 March 2017 
takes place in the presence of interleukin (IL-) 6, which drives the differentiation of $\mathrm{T}$ helper 17 (Th17) cells and can cause further inflammation in the body [8]. Interleukin (IL-) 17 is one of the Th17 cell cytokines. IL-17 and other Th17 cytokines play a role in many inflammatory and rheumatic diseases. In the presence of IL-1, IL-6, and TGF- $\beta$, Th17 cells are differentiated from naive CD4 cells [9].

Due to the dual role of TGF- $\beta$ and its association with both Th17 and Treg cells, abnormal TGF-Bl gene expression (the gene which encodes TGF- $\beta$, located on chromosome $19 q 13$ [10]) can be the cause of an autoinflammation in the body. However, abnormality in this expression can also be a defensive response of the immune system to preexisting inflammation in the body. The objective of the current study was to detect possible abnormalities in $T G F-B l$ gene expression. Determining the rates of $T G F-B I$ expression in AS patients can be a step towards understanding its role in AS pathogenesis so as to use the treatments that affect its pathway more efficiently.

\section{Materials and Methods}

\section{Study participants}

In this case-control study, 48 ankylosing spondylitis patients were selected conveniently from the outpatient clinic of the Rheumatology Research Center (RRC), Shariati Hospital, Tehran University of Medical Sciences (TUMS). Inclusion criteria were a BASDAI score $\geq 4$ (which indicates more disease activity) and a diagnosis based on the modified New York Criteria 1987 (mNYC) [11]. The exclusion criterion for cases was any previous usage of biologic drugs. The control group included 47 healthy individuals. The exclusion criteria for the control group were a personal or family history of rheumatologic, autoimmune or inflammatory diseases, and being younger than 18 years of age. The Human Ethics Committee of the Tehran University of Medical Science approved this study, and written informed consent was obtained from all participants. Age and gender variants were matched in the two groups.

Demographic, medical, familial, and pharmacological histories of the study subjects were recorded by a questionnaire. Indices including BASDAI (Bath Ankylosing Spondylitis Disease Activity Index), ASQoL (AS quality of life), BASMI (Bath Ankylosing Spondylitis Metrology Index), and BASFI (Bath Ankylosing Spondylitis Functional Index); were used to assess disease activity, quality of life, spinal mobility, and functional disability for each patient, respectively. Disease duration, presence of aphthous, family relationship, and ESR were also assessed.

\section{RNA extraction and Real time PCR}

A peripheral blood sample was collected from each participant. Mononuclear cells were immediately isolated by Ficoll-Hypaque. Total RNA was extracted from mononuclear cells using a High Pure RNA Isolation Kit (Roche life science product). The extracted RNA was then transcribed to complementary DNA (cDNA) using a Transcriptor First Strand cDNA Synthesis Kit (Roche life science product). SYBR Green Real Time PCR was performed on cDNA to assess $T G F-B 1$ gene expression. The relative $T G F-B 1$ gene expression was compared with Beta-2microglobulin expression as the housekeeping gene. The comparative $\mathrm{Ct}$ method was used to analyze gene expression data. Relative gene expression for each sample was calculated using the equation: $2^{-\Delta C t} \times 10^{3}$.

\section{Statistical analysis}

Quantitative variables were tested for normality with the Kolmogorov-Smirnov test and are expressed as mean \pm SD if normally distributed or as median $\pm \mathrm{IQR}$ (interquartile ranges) if not normally distributed. If the data did not have a normal distribution, the MannWhitney nonparametric test was performed to compare means of relative gene expression in the case and control groups. Correlations between TGF-BI gene expression and ESR, BASDAI, BASFI, BASMI and ASQoL were tested by Spearman's Rank-Order. Significance level was defined by a $P$-value of less than 0.05. All statistical analyses were done using SPSS version 23 and GraphPad Prism 6.

\section{Results}

\section{Characteristics of study participants}

Forty-eight ankylosing spondylitis patients (34 males and 14 females) with a disease duration of $12.29 \pm 9.4$ years and 47 healthy individuals (36 males and 11 females) as the control group participated in this study. The demographic data of the participants is demonstrated in Table 1. There were no significant differences between the two groups in the distribution of age and gender; ESR was significantly higher in cases $(P$-value $<0.001)$. Table 2 shows disease indices for ankylosing spondylitis patients. The pharmacological histories of the patients are shown in Table 3. 
Table 1. Comparison of demographic data between case and control groups

\begin{tabular}{|c|c|c|c|c|}
\hline \multicolumn{2}{|c|}{ Characteristics } & $\begin{array}{c}\text { Descriptive } \\
\text { statistics } \\
\text { cases } \\
(\mathbf{n}=48) \\
\end{array}$ & $\begin{array}{c}\text { Descriptive } \\
\text { statistics } \\
\text { controls } \\
(n=47)\end{array}$ & $\begin{array}{c}P- \\
\text { value }\end{array}$ \\
\hline \multicolumn{2}{|c|}{ Age $(\text { Year })^{1}$} & $40.0 \pm 11.21$ & $37.8 \pm 9.40$ & 0.30 \\
\hline \multirow[b]{2}{*}{ Smoking $^{2}$} & Smoker & $30(62.5 \%)$ & $16(34 \%)$ & \multirow[b]{2}{*}{0.004} \\
\hline & $\begin{array}{c}\text { Non- } \\
\text { Smoker }\end{array}$ & $18(37.5 \%)$ & $31(66 \%)$ & \\
\hline \multirow[t]{2}{*}{$\mathrm{Sex}^{2}$} & Male & $34(70 \%)$ & $36(76 \%)$ & \multirow{2}{*}{0.52} \\
\hline & Female & $14(30 \%)$ & $11(24 \%)$ & \\
\hline
\end{tabular}

Table 2. Clinical data of ankylosing spondylitis patients

\begin{tabular}{|c|c|c|}
\hline \multicolumn{2}{|c|}{ Characteristics } & Descriptive statistics \\
\hline \multicolumn{2}{|c|}{ Disease duration (Year) $^{1}$} & $12.29 \pm 9.4$ \\
\hline \multicolumn{2}{|c|}{ BASDAI score $^{1}$} & $4.26 \pm 2.2$ \\
\hline \multicolumn{2}{|c|}{ BASFI score $^{1}$} & $3.58 \pm 2.4$ \\
\hline \multicolumn{2}{|c|}{ BASMI score $^{1}$} & $4.86 \pm 1.9$ \\
\hline \multicolumn{2}{|l|}{$\mathrm{ESR}^{1,3}$} & $21 \pm 18.5$ \\
\hline \multirow{2}{*}{ Aphthous $^{2}$} & Presence & $31(64 \%)$ \\
\hline & Absence & $17(36 \%)$ \\
\hline
\end{tabular}

${ }^{\mathrm{I}}$ Mean \pm SD for continuous variables

${ }^{2}$ Number (Relative Frequency\%) for the categorical variables

${ }^{3}$ Erythrocyte Sedimentation Rate $(\mathrm{mm} / \mathrm{hr})$

Table 3. Descriptive statistics for pharmacological history of patients (Number (\%) for all pharmacological drug consumption)

\begin{tabular}{lll}
\hline Drug Name & Categories & N (\%) \\
\hline \multirow{2}{*}{ NSAIDs } & Using & $32(67 \%)$ \\
& Not Using & $16(33 \%)$ \\
Sulfasalazine & Using & $24(50 \%)$ \\
Corticosteroid & Not Using & $24(50 \%)$ \\
(prednisolone) & Using & $3(6.5 \%)$ \\
Intra-articular injection & Not Using & $45(93.5 \%)$ \\
(methyl prednisolone) & Not Using & $8(16.6 \%)$ \\
Methotrexate & Using & $40(83.4 \%)$ \\
& Not Using & $41(8.5 \%)$ \\
\hline
\end{tabular}

\section{Gene expression results}

The relative $T G F-B 1$ gene expression level was significantly higher in AS patients than in the control group $(P$-value $<0.0001)$. The change between cases and controls was 1.32-fold (Fig. 1).

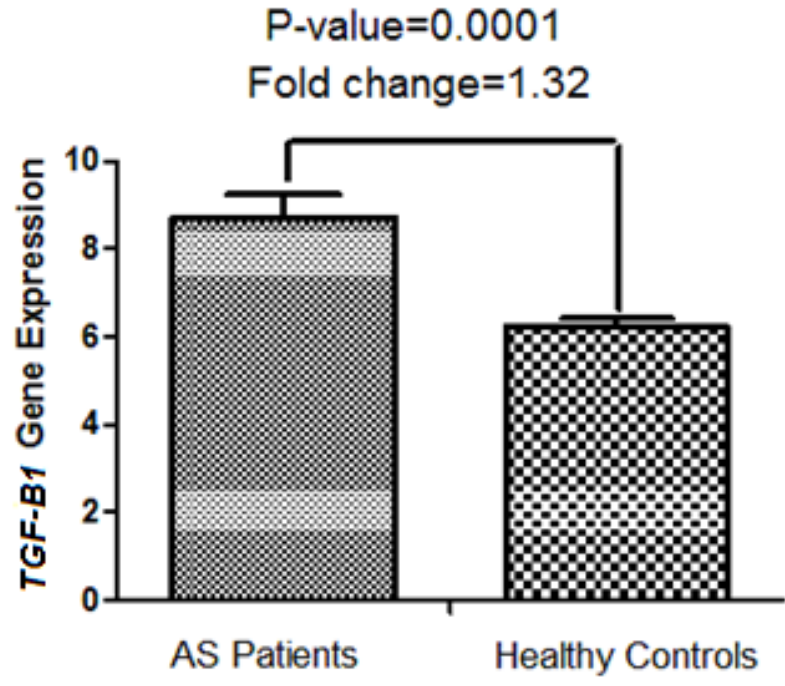

Fig. 1. Comparison of relative gene expression of $T G F-B 1$ in ankylosing spondylitis cases and controls

\section{Correlations between gene expression and clinical indices}

The correlations between $T G F-B 1$ gene expression and AS clinical indices are demonstrated in Table 4. There was no significant correlation between gene expression and clinical progression of the disease, however, there was a strong positive correlation between ASQoL and BASFI scores $(r=0.596, P$-value $<0.0001$; data not shown).

Table 4. Correlation between $T G F-B 1$ gene expression and AS clinical indices

\begin{tabular}{cccc}
\hline & Index & $\begin{array}{c}\text { Correlation } \\
\text { coefficient }\end{array}$ & $P$-value \\
\cline { 2 - 4 } TGF-B1 & BASDAI & 0.138 & 0.35 \\
gene & BASFI & 0.092 & 0.53 \\
expression & BASMI & -0.06 & 0.69 \\
& ASQol & 0.14 & 0.33 \\
& ESR & 0.09 & 0.55 \\
\hline
\end{tabular}

\section{Discussion}

The role of proinflammatory cytokines in inflammatory diseases such as ankylosing spondylitis is well known. TGF- $\beta$ is a cytokine with potential regulatory and inflammatory activities [8]. The inflammatory role of this cytokine takes place in the presence of IL-6, causing the differentiation of Th17 cells and thus causing further inflammation and augmentation of disease severity in autoimmune and inflammatory conditions. However, the most important and wellknown activity of TGF- $\beta$ is its immune regulatory 
activity [8]. The purpose of the current study was to compare $T G F-B 1$ gene expression in Iranian AS patients with healthy controls to learn its effects on the activity of AS. Other related surveys have mostly studied serum levels of cytokines or cytokine RNA production from immune cells and have attained controversial results about the cytokine effects on AS. The reason is likely to be the difficulty of measuring cytokine serum levels due to short cytokine half-lives and variations in measuring methods [12].

In the current study, the relative $T G F-B I$ gene expression was significantly higher in patients than in the control group. Based on the 1.32-fold change determined in this study, $T G F-B 1$ gene expression is $32 \%$ higher in the cases of this study.

Nevertheless, no significant linear correlation between $T G F-B 1$ gene expression and the clinical progression of AS disease was found. This is consistent with the study done in 2011 by Ali Taylan et al. on serum levels of $\mathrm{T}$ helper 17-related cytokines. They found significantly higher levels of TGF- $\beta$ and IL- 6 in AS patients compared to healthy individuals. However, no significant correlation between disease activity (measured by BASDAI) and the serum levels of TGF- $\beta$ was found in their study as well [13]. Nonetheless, the absence of a significant linear correlation does not reject the possibility of a correlation between TGF- $\beta$ in patients and their clinical progression. The pattern of progression in AS is not exactly predictable [14]. The inflammation is not constant in the course of the disease [15]. It might increase as the disease progresses, and it might also decline after spine restriction because of ankylosis. Therefore, the nonlinear correlation can possibly be present between TGF- $\beta$ and the clinical progression of AS disease, and further research is needed on the inflammation in the course of AS disease.

Regarding the dual role of TGF- $\beta$, the debate about the mechanism by which this cytokine affects AS disease can possibly be discussed through the recent usage of biologic drugs which have inhibitory effects on the inflammatory pathway of TGF- $\beta$ (activation of Th17, therefore causing further function of its cytokines), which has achieved favorable results [16]. Secukinumab, a human monoclonal antibody against interleukin 17A, was first approved for the treatment of psoriasis and psoriatic arthritis in 2014. It is also being investigated for the treatment of $\mathrm{AS}$, but so far, the studies have not provided sufficient data to prove Secukinumab efficacy on AS [17, 18]. However, in a study by Baeten et al., Secukinumab caused a rapid reduction in the clinical and biological signs of active AS [16]. The effectiveness of Secukinumab in AS was also stated by Blair et al. in their 2016 study [19].

Controversially, Medhat Shehata et al. found a significant increase of TGF- $\beta$ in AS patients who had responded to a special therapeutic method, and their diseases turned inactive compared to the group who had not responded to the therapy. This suggests that TGF- $\beta$ plays an anti-inflammatory role in AS disease [20]. This result is consistent with the Brown et al. review of the role of non-major-histocompatibilitycomplex genes in AS. According to this study, TGF- $\beta$ plays a small role in the pathogenesis of ankylosing spondylitis, and some other explanation exists for the linkage between TGF- $\beta$ and AS disease [21].

In the present study, a matched control group was used to reduce confounding bias. However, the small sample size can possibly lead to less external validity. Convenient sampling was also a limitation in the present study.

\section{Conclusion}

This study purposed to investigate the expression of $T G F-B 1$ gene in ankylosing spondylitis. It can be concluded that the increase of this cytokine in AS patients with active disease can possibly demonstrate its activity in the disease. This activity can be a regulatory role as a response to inflammation in the body or the augmentation of inflammation which exacerbates the disease. Therefore, further research needs to be done in this field to resolve this dilemma.

\section{Conflicts of interest}

The author declares no conflicts of interest.

\section{Acknowledgment}

This study was supported by a research grant (grant NO: 93-02-41-24481) from the Deputy of Research of Tehran University of Medical Sciences.

\section{References}
1. Braun J, Sieper J. Ankylosing spondylitis. The Lancet 2007; (9570): 1379-90. doi: 10.1016/S0140-6736(07)60635-7.
2. Hajjaj-Hassouni N, Burgos-

\author{
Vargas R. Ankylosing spondylitis \\ and reactive arthritis in the \\ developing world. Best Practice \\ \& Research Clinical \\ Rheumatology 2008; 22(4): 709-
}

23. doi: http://dx.doi.org/10.1016/ j.berh.2008.05.005.

3. Davatchi F, Jamshidi AR, Banihashemi AT, Gholami J, Forouzanfar MH, Akhlaghi M. et 
al. WHO-ILAR COPCORD Study (Stage 1, Urban Study) in Iran. J Rheumatol 2008; 35(7): 1384.

4. Nicknam MH, Mahmoudi $M$ Amirzargar AA, Ganjalikhani Hakemi M, Khosravi F, Jamshidi AR. et al. Determination of HLAB27 subtypes in Iranian patients with ankylosing spondylitis. Iran J Allergy Asthma Immunol 2008; 7(1): 19-24. doi: 07.01/ ijaai.1924.

5. Joyce ME, Jingushi S, Bolander ME. Transforming growth factorbeta in the regulation of fracture repair. Orthop Clin North Am 1990; 21(1): 199-209.

6. van Vlasselaer P, Punnonen J, de Vries JE. Transforming growth factor-beta directs $\operatorname{IgA}$ switching in human B cells. The Journal of Immunology 1992; 148(7): 206267.

7. Archer JR. Ankylosing spondylitis, $\operatorname{Ig} \mathrm{A}, \quad$ and transforming growth factors. Ann Rheum Dis 1995; 54(7): 544-6. doi: 10.1136/ard.54.7.544.

8. Sanjabi S, Zenewicz LA, Kamanaka M, Flavell RA. Antiand Pro-inflammatory Roles of TGF- $\beta$, IL-10, and IL-22 In Immunity and Autoimmunity. Curr Opin Pharmacol 2009; 9(4): 447-53. doi: 10.1016/j.coph. 2009.04.008.

9. Onishi RM, Gaffen SL Interleukin-17 and its target genes: mechanisms of interleukin17 function in disease. Immunology 2010; 129(3): 31121. doi: 10.1111/j.1365-2567. 2009.03240.x.

10. Massague J. The transforming growth factor-beta family. Annu Rev Cell Biol 1990; 6: 597-641. doi: 10.1146/annurev.cb.06. 110190.003121

11. Akgul $\mathrm{O}$, Ozgocmen $\mathrm{S}$. Classification criteria for spondyloarthropathies. World J Orthop 2011; 2(12): 107-15. doi: 10.5312/wjo.v2.i12.07.

12. Keller C, Webb A, Davis J. Cytokines in the seronegative spondyloarthropathies and their modification by TNF blockade: a brief report and literature review. Ann Rheum Dis 2003; 62(12): 1128-32. doi: 10.1136/ard.2003. 011023.

13. Taylan A, Sari I, Kozaci DL, Yuksel A, Bilge S, Yildiz Y. et al. Evaluation of the $\mathrm{T}$ helper 17 axis in ankylosing spondylitis. Rheumatol Int 2012; 32(8): 2511-5. doi: 10.1007/s00296-0111995-7.

14. Sieper J, Braun J, Rudwaleit M, Boonen A, Zink A. Ankylosing spondylitis: an overview. Ann Rheum Dis 2002; 61 (Suppl 3): iii8-iii18. doi: 10.1136/ard.61. suppl 3.iii8.

15. Carette S, Graham D, Little H, Rubenstein J, Rosen P. The natural disease course of ankylosing spondylitis. Arthritis Rheum 1983; 26(2): 186-90. doi: 10.1002/art.1780260210.

16. Baeten D, Baraliakos X, Braun J, Sieper J, Emery P, van der Heijde D. et al. Anti-interleukin-17A monoclonal antibody secukinumab in treatment of ankylosing spondylitis: a randomised, double-blind, placebo-controlled trial. Lancet 2013; 382 (9906): 1705-13. doi: 10.1016/s0140-6736(13)61134-4.

17. Chen C, Zhang X, Xiao L, Zhang $X$, Ma X. Comparative Effectiveness of Biologic Therapy Regimens for Ankylosing Spondylitis: A Systematic Review and a Network Meta-Analysis. Medicine (Baltimore) 2016; 95(11): e3060. doi: 10.1097/md. 0000000000003060.

18. Sanford M, McKeage K. Secukinumab: first global approval. Drugs 2015; 75(3): 329-38. doi: 10.1007/s40265-0150359-0.

19. Blair HA, Dhillon S. Secukinumab: A Review in Ankylosing Spondylitis. Drugs 2016; 76(10): 1023-30. doi: 10. 1007/s40265-016-0598-8.

20. Shehata M, Schwarzmeier JD, Hilgarth M, Demirtas D, Richter D, Hubmann R. et al. Effect of combined spa-exercise therapy on circulating TGF-beta1 levels in patients with ankylosing spondylitis. Wien Klin Wochenschr 2006; 118 (9-10): 266-72. doi: 10.1007/s00508-0060560-y.

21. Brown MA. Non-majorhistocompatibility-complex genetics of ankylosing spondylitis. Best Pract Res Clin Rheumatol 2006; 20(3): 611-21. doi: 10.1016/j.berh.2006.03.005. 